Cronfa - Swansea University Open Access Repository

This is an author produced version of a paper published in :

Surgery for Obesity and Related Diseases

Cronfa URL for this paper:

http://cronfa.swan.ac.uk/Record/cronfa19813

\title{
Paper:
}

Mallipedhi, A., Prior, S., Barry, J., Caplin, S., Baxter, J. \& Stephens, J. (2014). Changes in inflammatory markers after sleeve gastrectomy in patients with impaired glucose homeostasis and type 2 diabetes. Surgery for Obesity and Related Diseases, 10(6), 1123-1128.

http://dx.doi.org/10.1016/j.soard.2014.04.019

This article is brought to you by Swansea University. Any person downloading material is agreeing to abide by the terms of the repository licence. Authors are personally responsible for adhering to publisher restrictions or conditions. When uploading content they are required to comply with their publisher agreement and the SHERPA RoMEO database to judge whether or not it is copyright safe to add this version of the paper to this repository. http://www.swansea.ac.uk/iss/researchsupport/cronfa-support/ 


\section{Changes in inflammatory markers after sleeve gastrectomy in subjects with impaired glucose homeostasis and type 2 diabetes}

\section{Short title: Inflammatory markers after sleeve gastrectomy}

Akhila Mallipedhi MRCP ${ }^{1,2}$; Sarah L Prior PhD ${ }^{1}$; Jonathan Barry $\mathrm{MCh}^{3}$; Scott Caplin $\mathrm{FRCS}^{3}$; John N Baxter $\mathrm{MD}^{3}$; Jeffrey W Stephens FRCP ${ }^{1,2,3}$

${ }^{1}$ Diabetes Research Group, Institute of Life Sciences, Swansea University, Swansea SA2 8PP, UK.

${ }^{2}$ Department of Diabetes \& Endocrinology, Morriston Hospital ABM University Health Board, Swansea SA6 6NL, UK.

${ }^{3}$ Welsh Institute of Metabolic and Obesity Surgery, Morriston Hospital ABM University Health Board, Swansea SA6 6NL, UK.

\section{Correspondence and reprint requests to:}

Dr.Akhila Mallipedhi

Diabetes Research Group, Institute of Life Sciences, Swansea University, Swansea SA2 8PP, UK

Tel: +44 (0)1792 704078; Fax: +44 (0)1792 703214

E-mail: mallipedhi@doctors.org.uk

Conflict of interest: The authors declare that there is no conflict of interest associated with this manuscript.

Source of funding: This study was supported by a project Research Grant from The BUPA Foundation (33NOV06)

\section{Acknowledgements:}

Gareth Dunseath MPhil ${ }^{1}$; Richard M Bracken $\mathrm{PhD}^{1}$; Kathie Wareham $\mathrm{MSc}^{3}$; Jane Griffiths $\mathrm{BSc}^{3}$; Nia Eyre $\mathrm{BSc}^{4}$; Morgan J FRCA, MRCP ${ }^{4}$; Alam I MD, $\mathrm{FRCS}^{4}$; Rice S PhD, MRCP ${ }^{5}$; Stephen C Bain MD FRCP $^{1}$; Steve D Luzio $\mathrm{PhD}^{1}$

\footnotetext{
${ }^{1}$ Diabetes Research Group, Institute of Life Sciences, Swansea University, Swansea SA2 8PP, UK.

${ }^{2}$ Department of Diabetes \& Endocrinology, Morriston Hospital ABM University Health Board, Swansea SA6 6NL, UK.

${ }^{3}$ Clinical Research Unit, Morriston Hospital, ABM University Health Board, Swansea SA6 6NL, UK.

${ }^{4}$ Welsh Institute of Metabolic and Obesity Surgery, Morriston Hospital ABM University Health Board, Swansea SA6 6NL, UK.

${ }^{5}$ Department of Diabetes \& Endocrinology, Hywel Dda Health Board, Llanelli, Carmarthenshire SA14 8QF, UK.
} 


\title{
Changes in inflammatory markers after sleeve gastrectomy in subjects with impaired glucose homeostasis and type 2 diabetes
}

Source of funding: This study was supported by a project Research Grant from the BUPA Foundation (33NOV06).

Conflict of interest: The authors declare that there is no conflict of interest associated with this manuscript.

\begin{abstract}
Background: Bariatric surgery is an effective treatment for morbid obesity. Obesity and type 2 diabetes are associated with chronic inflammation. There is lack of data examining the effects of sleeve gastrectomy (SG) on inflammatory biomarkers.

Objectives: Our aim was to study the effects of SG on specific cytokines associated with obesity including interleukin-6 (IL-6), interleukin-10 (IL-10), leptin, adiponectin and Creactive protein (CRP) preoperatively, 1 and 6 months after surgery.

Setting: University Hospital, United Kingdom.

Methods: A non-randomized prospective study comprising of 22 participants with impaired glucose homeostasis and type 2 diabetes undergoing SG (body mass index [BMI] $50.1 \mathrm{~kg} / \mathrm{m}^{2}$, Glycated hemoglobin $\left.\left[\mathrm{HbA}_{1 \mathrm{c}}\right] 53 \mathrm{mmol} / \mathrm{mol}\right)$. Serial measurements of IL-6, IL-10, leptin, adiponectin, and CRP were performed during oral glucose tolerance testing pre-operatively, 1 and 6 months postoperatively.
\end{abstract}


Results: We observed significant improvements at 1 and 6 months in leptin $(p=<0.001)$ and CRP ( $p=0.003$ ) following SG. We also observed a significant reduction in IL-6 at 6 months $(\mathrm{p}=0.001)$. No statistically significant differences were observed for adiponectin and IL-10. Conclusion: This study is the first to examine the detailed changes in the inflammatory cytokines after SG. Our study shows significant improvements in the inflammatory biomarkers following SG in subjects with impaired glucose homeostasis and type 2 diabetes.

\section{Keywords}

Obesity; Type 2 diabetes mellitus; Sleeve Gastrectomy; Inflammation

\section{Introduction}

Systemic inflammation is closely associated with obesity and type 2 diabetes mellitus (T2DM). Prospective studies have shown that chronic low grade systemic inflammation predicts the future risk of impaired glucose tolerance (IGT), T2DM ${ }^{(1)}$ and cardiovascular disease (CVD) ${ }^{(2)}$. Certain subgroups of the population that are at a high risk of developing T2DM have elevated inflammatory markers. These include overweight adults and children, women with polycystic ovary syndrome, certain ethnic origins (e.g. Pima Indians) and participants with a family history of T2DM ${ }^{(3)}$. Interestingly, these groups often also share the common feature of obesity. The Finnish and American Diabetes Prevention studies both showed a $58 \%$ reduction in progression from IGT to T2DM, by diet and exercise ${ }^{(4,5)}$. In addition, several of the studies looking at CVD risk reduction with statins (WOSCOPS) and angiotensin-1 converting enzyme inhibitors (HOPE, CAPP) showed a 25-30\% reduction in the development of $\mathrm{T} 2 \mathrm{DM}{ }^{(6-8)}$, presumably through an underlying anti-inflammatory 
mechanism. These previously described results reinforce the close relationship between obesity, inflammation and T2DM.

Adipokines are cytokines secreted by adipose tissue and can modulate immune response, insulin sensitivity and energy balance. Cytokines associated with obesity include interleukin6 (IL-6), interleukin-10 (IL-10), adiponectin, leptin and C-reactive protein (CRP) ${ }^{(9-11)}$. Changes in plasma levels of pro-inflammatory and anti-inflammatory cytokines and adipokines are related to increased adipose tissue mass ${ }^{(1,2)}$.

Bariatric surgery is effective in the treatment of obesity and T2DM and in reducing CVD risk factors ${ }^{(12)}$. This is likely to occur through a reduction in adipose tissue mass and subsequent improvements in the inflammatory milieu $(13,14)$. Previous work has demonstrated malabsorptive surgery such as Laparoscopic Roux-en-Y Gastric Bypass (RYGB) is associated with significant reductions in serum levels of leptin and non-significant changes in soluble TNF- $\alpha$ receptor- 1 and adiponectin levels 6 months following surgery ${ }^{(15)}$. CRP has also been observed to be significantly lower at 6 months compared to preoperative values. A significant reduction in CRP, IL-6 and an increase in adiponectin have also been observed 6 months after gastric bypass in another study ${ }^{(16)}$ and is supported by the results of a recent meta-analysis ${ }^{(17)}$. Over recent years an increasing number of SG operations have been performed relative to RYGB, Bilio-pancreatic Diversion (BPD) and laparoscopic adjustable Gastric Banding (LAGB) and furthermore SG is now recognized as a stand-alone bariatric procedure with a superior safety profile ${ }^{(18,19)}$. Prospective studies describe a reduction in CRP at 4 weeks in 11 patients following a $\mathrm{SG}^{(20)}$ and in 37 participants at 9 months ${ }^{(21)}$. An improvement in CRP has also been observed in a retrospective hospital database study of 61 patients ${ }^{(22)}$. However, there is limited information within the available literature with regard to the effects of SG on other cytokines and adipokines. 
Our aim was to specifically examine the temporal changes in IL-6, IL-10, leptin, adiponectin and CRP preoperatively, 1 and 6 months after SG in a sample of subjects with impaired glucose tolerance or T2DM.

\section{Participants and methods}

\section{Study participants}

Approval for the study was obtained from the Local Research Ethics Committee (South Wales; LREC reference 06/WMW02/7) and the Joint Scientific Research Committee at Swansea University and ABM University Health Board. Participants were identified and recruited from patients undergoing a planned bariatric surgical procedure at Welsh Institute of Metabolic and Obesity Surgery (WIMOS) at Morriston Hospital, ABM University Health Board, Swansea, Wales, UK. Entry criteria at the outset of the study included:- both sexes, age $20-40$ years, BMI $>40 \mathrm{~kg} / \mathrm{m}^{2}$ and physically fit for surgery. Participants with any acute concurrent illness were excluded. Participants with previously diagnosed T2DM treated with diet, oral agents, GLP-1 analogues or insulin were included. All participants underwent an oral glucose tolerance test (OGTT) prior to recruitment. Participants with impaired glucose regulation were those with either impaired fasting glycaemia $(5.6-6.9 \mathrm{mmol} / \mathrm{L})$ or impaired glucose tolerance (2-hour glucose $7.8-11.0 \mathrm{mmol} / \mathrm{L})^{(23)}$.

\section{Study design}

Participants with a planned SG were recruited prospectively and consecutively from the bariatric surgical clinic. SG is a standard sleeve i.e. sleeve fashioned around a 32F bougie taken from $5 \mathrm{~cm}$ proximal to the pylorus and up to the left crus. All participants were recruited 
pre-operatively (within 1 month of surgery) and followed up postoperatively at 1 and 6 months. All participants with the help of the research nurse completed a baseline questionnaire and all clinical measurements were documented during the visits. All blood samples were collected after stopping any prescribed insulin or oral hypoglycaemic agent for 24 hours prior to an OGTT performed with $75 \mathrm{~g}$ of glucose $(122 \mathrm{mLs}$ of Polycal $61.9 \mathrm{~g} / 100 \mathrm{~mL}$ of glucose, Nutricia Clinical Care, Trowbridge, UK).

\section{Baseline clinical and biochemical information}

At the time of screening the following clinical information was ascertained: age, gender, past medical history, treatment and duration of diabetes. Baseline clinical measurements consisted of weight, height, BMI, waist circumference, systolic and diastolic blood pressure. Baseline biochemical measurements (total cholesterol, Low density lipoprotein-cholesterol [LDL-C], High density lipoprotein-cholesterol [HDL-C] and triglycerides) were analyzed within the local hospital accredited laboratory. Glucose and lipids (Roche Modular P800 Analyzer) and

insulin and C-peptide (Roche E170 Modular Analyzer) were also measured locally. All blood samples were collected on ice, centrifuged and separated within one hour of collection and subsequently stored at $-80^{\circ} \mathrm{C}$ until analysis. Fasting EDTA samples were collected for the measurement of cytokines during the OGTT at baseline, 1 and 6 months.

\section{Measurement of total cytokines}

Fasting plasma levels of IL-6, IL-10 and leptin were measured with high sensitivity ELISA kits (R\&D Systems). Intra-assay and inter-assay variability coefficients were as follows: IL-6 $\leq 4.2 \%$ and $\leq 6.4 \%$; IL- $10, \leq 5.0 \%$ and $\leq 7.5 \%$; leptin, $\leq 3.3 \%$ and $\leq 5.4 \%$.

Fasting plasma levels of total adiponectin and CRP were measured with high sensitivity ELISA kits (Immundiagnostik AG). Intra-assay and inter-assay variability coefficients were 
as follows: adiponectin, $\leq 3.4 \%$ and $\leq 6.3 \%$; CRP, $\leq 6.0 \%$ and $\leq 13.8 \%$. All samples were assayed in duplicate.

\section{Statistical methods}

Statistical analysis was performed using SPSS (version 10.1, SPSS Inc., Chicago). Results for continuous variables are presented as mean and standard deviation and in graphical representation as mean and standard error. Continuous variables that did not have a normal distribution (triglyceride, adiponectin, CRP and IL-6) underwent log transformation to normalize the data for analysis and are described with the geometric mean and approximate standard deviation. For continuous variables, the mean temporal changes were compared between baseline and 1 or 6 months using a paired t-test. Categorical data were analysed using a Chi-squared test. Paired t-tests were used to compare mean differences in cytokines between baseline, 1 and 6 months for IL-10, leptin, adiponectin, CRP and IL-6 (with log transformation where appropriate). In all cases a $\mathrm{p}<0.05$ was considered statistically significant.

\section{Results}

\section{Subject characteristics}

A total of 22 participants who underwent a SG (mean age $48 \pm 7$ years) with impaired glucose homeostasis or T2DM (median duration of 42 month [interquartile range 21-66 months]) completed the study. Table 1 shows the temporal changes between baseline, 1 and 6 months within the group. As shown in Table 1, significant reductions were observed in weight at 1 month with a mean reduction in BMI of $10.5 \mathrm{~kg} / \mathrm{m}^{2}$ (weight change of $31.1 \mathrm{~kg}$ ) at 6 months. 
We also observed a significant reduction in the systolic blood pressure at 1 month but no significant changes in total cholesterol, LDL-C or triglyceride concentrations. Significant changes were observed in fasting glucose, 2-hour glucose and $\mathrm{HbA}_{1 \mathrm{c}}$.

\section{Temporal changes in inflammatory cytokines following sleeve gastrectomy}

The temporal changes in fasting inflammatory cytokines between baseline, 1 and 6 months are shown in Figure 1. Plasma leptin decreased by $34.4 \%$ and $43.1 \%$ respectively at 1 and 6 months postoperatively. Compared to baseline, significant reductions of $67.5 \%$ and $44.8 \%$ were observed for CRP respectively. At 6 months there was a significant reduction $(31.6 \%)$ in plasma IL-6. There was a non-significant increase of adiponectin at 6 months $(p=0.15)$. No significant changes were observed in IL-10.

\section{Discussion}

Bariatric surgery in addition to weight loss effectively reduces morbidity and mortality in severely obese individuals with favorable effects on T2DM, hypertriglyceridaemia and hypertension. These effects are likely to be related to an improvement in the inflammatory profile caused by the rapid and significant reductions in fat mass following surgery ${ }^{(16)}$. SG has gained recent popularity as an independent bariatric procedure ${ }^{(18,19)}$. We observed significant improvements in leptin and CRP at 1 month postoperatively following SG and this was maintained at 6 months. We also observed a reduction in IL-6 at 1 month which was statistically significant at 6 months. No differences were observed for adiponectin and IL-10 following SG. Previous studies have only described changes in CRP as early as 4 weeks following a $\mathrm{SG}^{(20-22)}$.

We also examined the correlations between the change in BMI with the inflammatory biomarkers. At 1 month, there was a significant correlation between greater weight loss and 
increased plasma IL-10 $(\mathrm{r}=0.50, \mathrm{p}=0.008)$ and an inverse association between increased adiponectin and IL-6 $(r=-0.50, p=0.04)$, such that an increase in adiponectin was associated with reduction in IL-6. These changes would be consistent with a reduction in adipose tissue mass being responsible for increased levels of the anti-inflammatory adipokine adiponectin and a reduction in the proinflammatory cytokine IL-6. This is in line with previous studies which have demonstrated that adipose tissue is a major source of IL-6 with as much as $30 \%$ of circulating IL-6 being derived from adipose tissue (24). Circulating levels of IL-6 are raised in insulin resistant states such as obesity ${ }^{(25)}$, IGT ${ }^{(26)}$ and T2DM ${ }^{(27-29)}$ and previous prospective studies have shown plasma IL-6 to correlate with BMI, percentage fat mass and fasting insulin levels. Weight reduction by diet and exercise has also been shown to reduce plasma IL-6 levels ${ }^{(30)}$.

This study is the first to examine the temporal relationship of these inflammatory biomarkers at 1 and 6 months following SG. This current study contributes to the available literature supporting the role of SG for the treatment of T2DM, and pro-inflammatory conditions associated with morbid obesity. One limitation of the study was that the sample group was heterogeneous comprising of subjects with impaired glucose tolerance and type 2 diabetes. Furthermore, the duration of diabetes was variable within the study group (median 42 months [interquartile range 21-66 months]) and that this might have an effect on the levels of inflammatory markers pre-operatively. Furthermore, the duration of diabetes was obtained from primary care medical records and this is therefore an estimate as diabetes may be present for sometime before the diagnosis is made ${ }^{(31)}$.

Further prospective studies are required to examine the effects of $\mathrm{SG}$ in relation to biomarkers of inflammation and oxidative stress in relation to inflammatory medicated complications of obesity. 
Table 1: Baseline and end of study clinical and biochemical measurements within the SG group

\begin{tabular}{|c|c|c|c|c|c|}
\hline Measurement & Baseline & 1 month & ${ }^{\mathrm{a}} \mathrm{P}$ & 6 months & ${ }^{b} \mathrm{P}$ \\
\hline Weight (kg) & $146.6(29.6)$ & $129.4(26.9)$ & $<0.001$ & $115.5(24.4)$ & $<0.001$ \\
\hline BMI $\left(\mathrm{kg} / \mathrm{m}^{2}\right)$ & $50.1(6.6)$ & $44.0(6.6)$ & $<0.001$ & $39.6(6.2)$ & $<0.001$ \\
\hline Waist (cm) & $138(18)$ & $128(17)$ & $<0.001$ & $118(18)$ & $<0.001$ \\
\hline Systolic BP (mmHg) & $131(18)$ & $123(14)$ & 0.04 & $128(20)$ & 0.12 \\
\hline Diastolic BP (mmHg) & $76(11)$ & $74(9)$ & 0.63 & $73(14)$ & 0.13 \\
\hline Cholesterol (mmol/L) & $4.3(1.0)$ & $4.4(1.1)$ & 0.58 & $4.7(1.2)$ & 0.09 \\
\hline LDL-C (mmol/L) & $2.4(0.8)$ & $2.7(1.0)$ & 0.16 & $2.8(0.9)$ & 0.05 \\
\hline $\mathrm{HDL}-\mathrm{C}(\mathrm{mmol} / \mathrm{L})$ & $1.2(0.3)$ & $1.1(0.3)$ & 0.02 & $1.3(0.3)$ & 0.10 \\
\hline Triglyceride $(\mathrm{mmol} / \mathrm{L})^{\mathrm{c}}$ & $1.4(0.4)$ & $1.4(0.2)$ & 0.92 & $1.1(0.2)$ & 0.15 \\
\hline $\mathrm{HbA}_{1 \mathrm{c}}(\%)$ & $7.0(1.7)$ & $6.1(0.8)$ & 0.005 & $5.7(0.8)$ & 0.002 \\
\hline $\mathrm{HbA}_{\mathrm{lc}}(\mathrm{mmol} / \mathrm{mol})$ & $53(18.6)$ & $43(8.7)$ & 0.005 & $39(8.7)$ & 0.002 \\
\hline Fasting glucose (mmol/L) & $7.6(3.6)$ & $5.4(0.9)$ & 0.02 & $5.0(1.0)$ & 0.08 \\
\hline 2-hour glucose (mmol/L) & $11.6(5.9)$ & $7.8(3.4)$ & 0.002 & $5.4(2.2)$ & $<0.001$ \\
\hline
\end{tabular}

Mean and standard deviation shown for continuous variables

${ }^{\mathrm{a}} \mathrm{P}$-value comparing baseline with 1 months.

${ }^{\mathrm{b}} \mathrm{P}$-value comparing baseline with 6 months.

${ }^{c} \log$ transformed for analysis. Geometric mean and approximate standard deviation shown for log- transformed data.

In the group there were 15 females and 7 males.

$\mathrm{BMI}=$ Body mass index, LDL-C $=$ Low density lipoprotein-Cholesterol, HDL-C $=$ High density lipoprotein-Cholesterol, $\mathrm{HbA}_{1 \mathrm{c}}=$ Glycated hemoglobin 


\section{Figure legends}

\section{Figure 1: Temporal changes in inflammatory biomarkers following sleeve gastrectomy}

Mean and standard error is shown.

${ }^{*} \mathrm{P}<0.05$ : Significant changes relative to baseline.

Figure 1a: Interleukin-10.

Figure 1b: Leptin

Figure 1c: Adiponectin

Figure 1d: C-reactive protein

Figure 1e: Interleukin-6

\section{References}

1. Freeman D, Norrie J, Caslake M, Gaw J, Ford I, Lowe G, et al. C-reactive protein is an independent predictor of risk for the development of diabetes in the West of Scotland Coronary Prevention Study. Diabetes. 2002;51:1596-600.

2. Kaptoge S, Di Angelantonio E, Pennells L, Wood AM, White IR, Gao P, et al. Creactive protein, fibrinogen, and cardiovascular disease prediction. N Engl J Med. 2012 Oct 4;367(14):1310-20.

3. Sattar N, Perry C, Petrie J. Type 2 diabetes an inflammatory disorder. Br J Diabetes Vasc Dis. 2003;3:36-41.

4. Tuomilehto J, Lindstrom J, Eriksson JG, Valle TT, Hamalainen H, Ilanne-Parikka P, et al. Prevention of type 2 diabetes mellitus by changes in lifestyle among subjects with impaired glucose tolerance. N Engl J Med. 2001 May 3;344(18):1343-50.

5. Knowler WC, Barrett-Connor E, Fowler SE, Hamman RF, Lachin JM, Walker EA, et al. Reduction in the incidence of type 2 diabetes with lifestyle intervention or metformin. $\mathrm{N}$ Engl J Med. 2002 Feb 7;346(6):393-403.

6. Freeman DJ, Norrie J, Sattar N, Neely RD, Cobbe SM, Ford I, et al. Pravastatin and the development of diabetes mellitus: evidence for a protective treatment effect in the West of Scotland Coronary Prevention Study. Circulation. 2001 Jan 23;103(3):357-62.

7. Yusuf S, Gerstein H, Hoogwerf B, Pogue J, Bosch J, Wolffenbuttel BH, et al. Ramipril and the development of diabetes. JAMA. 2001 Oct 17;286(15):1882-5.

8. Hansson L, Lindholm LH, Niskanen L, Lanke J, Hedner T, Niklason A, et al. Effect of angiotensin-converting-enzyme inhibition compared with conventional therapy on cardiovascular morbidity and mortality in hypertension: the Captopril Prevention Project (CAPPP) randomised trial. Lancet. 1999 Feb 20;353(9153):611-6. 
9. Rabe K, Lehrke M, Parhofer KG, Broedl UC. Adipokines and insulin resistance. Mol Med. 2008 Nov-Dec;14(11-12):741-51.

10. Hotamisligil GS, Shargill NS, Spiegelman BM. Adipose expression of tumor necrosis factor-alpha: direct role in obesity-linked insulin resistance. Science. 1993 Jan $1 ; 259(5091): 87-91$.

11. Hotamisligil GS, Spiegelman BM. Tumor necrosis factor alpha: a key component of the obesity-diabetes link. Diabetes. 1994 Nov;43(11):1271-8.

12. Buchwald H, Avidor Y, Braunwald E, Jensen MD, Pories W, Fahrbach K, et al. Bariatric surgery: a systematic review and meta-analysis. JAMA. 2004 Oct 13;292(14):172437.

13. Cottam DR, Mattar SG, Barinas-Mitchell E, Eid G, Kuller L, Kelley DE, et al. The chronic inflammatory hypothesis for the morbidity associated with morbid obesity: implications and effects of weight loss. Obes Surg. 2004 May;14(5):589-600.

14. Esposito K, Giugliano G, Scuderi N, Giugliano D. Role of adipokines in the obesityinflammation relationship: the effect of fat removal. Plast Reconstr Surg. 2006 Sep 15;118(4):1048-57; discussion 58-9.

15. Miller GD, Nicklas BJ, Fernandez A. Serial changes in inflammatory biomarkers after Roux-en-Y gastric bypass surgery. Surg Obes Relat Dis. 2011 Sep-Oct;7(5):618-24.

16. Illan-Gomez F, Gonzalvez-Ortega M, Orea-Soler I, Alcaraz-Tafalla MS, AragonAlonso A, Pascual-Diaz M, et al. Obesity and inflammation: change in adiponectin, Creactive protein, tumour necrosis factor-alpha and interleukin-6 after bariatric surgery. Obes Surg. 2012 Jun;22(6):950-5.

17. Rao SR. Inflammatory markers and bariatric surgery: a meta-analysis. Inflamm Res. 2012 Aug;61(8):789-807.

18. Deitel M, Crosby RD, Gagner M. The First International Consensus Summit for Sleeve Gastrectomy (SG), New York City, October 25-27, 2007. Obes Surg. 2008 May;18(5):487-96.

19. Gumbs AA, Gagner M, Dakin G, Pomp A. Sleeve gastrectomy for morbid obesity. Obes Surg. 2007 Jul;17(7):962-9.

20. Bueter M, Dubb SS, Gill A, Joannou L, Ahmed A, Frankel AH, et al. Renal cytokines improve early after bariatric surgery. Br J Surg. 2010 Dec;97(12):1838-44.

21. Wong AT, Chan DC, Armstrong J, Watts GF. Effect of laparoscopic sleeve gastrectomy on elevated C-reactive protein and atherogenic dyslipidemia in morbidly obese patients. Clin Biochem. 2011 Mar;44(4):342-4.

22. Hakeam HA, O'Regan PJ, Salem AM, Bamehriz FY, Eldali AM. Impact of laparoscopic sleeve gastrectomy on iron indices: 1 year follow-up. Obes Surg. 2009 Nov;19(11):1491-6.

23. Standards of medical care in diabetes--2013. Diabetes Care. 2013 Jan;36 Suppl 1:S1166.

24. Mohamed-Ali V, Pinkney JH, Coppack SW. Adipose tissue as an endocrine and paracrine organ. Int J Obes Relat Metab Disord. 1998 Dec;22(12):1145-58.

25. Mohamed-Ali V, Goodrick S, Rawesh A, Katz DR, Miles JM, Yudkin JS, et al. Subcutaneous adipose tissue releases interleukin-6, but not tumor necrosis factor-alpha, in vivo. J Clin Endocrinol Metab. 1997 Dec;82(12):4196-200.

26. Muller S, Martin S, Koenig W, Hanifi-Moghaddam P, Rathmann W, Haastert B, et al. Impaired glucose tolerance is associated with increased serum concentrations of interleukin 6 and co-regulated acute-phase proteins but not TNF-alpha or its receptors. Diabetologia. 2002 Jun;45(6):805-12. 
27. Pickup JC, Mattock MB, Chusney GD, Burt D. NIDDM as a disease of the innate immune system: association of acute-phase reactants and interleukin-6 with metabolic syndrome X. Diabetologia. 1997 Nov;40(11):1286-92.

28. Fernandez-Real JM, Ricart W. [An increased proinflammatory activity is inherent in insulin resistance]. Med Clin (Barc). $2000 \mathrm{Jul}$ 1;115(5):185-9.

29. Vozarova B, Fernandez-Real JM, Knowler WC, Gallart L, Hanson RL, Gruber JD, et al. The interleukin-6 (-174) G/C promoter polymorphism is associated with type-2 diabetes mellitus in Native Americans and Caucasians. Hum Genet. 2003 Apr;112(4):409-13.

30. Monzillo LU, Hamdy O, Horton ES, Ledbury S, Mullooly C, Jarema C, et al. Effect of lifestyle modification on adipokine levels in obese subjects with insulin resistance. Obes Res. 2003 Sep;11(9):1048-54.

31. Harris MI. Diabetes in America: epidemiology and scope of the problem. Diabetes Care. 1998 Dec;21 Suppl 3:C11-4. 
Figure 1a: Interleukin-10

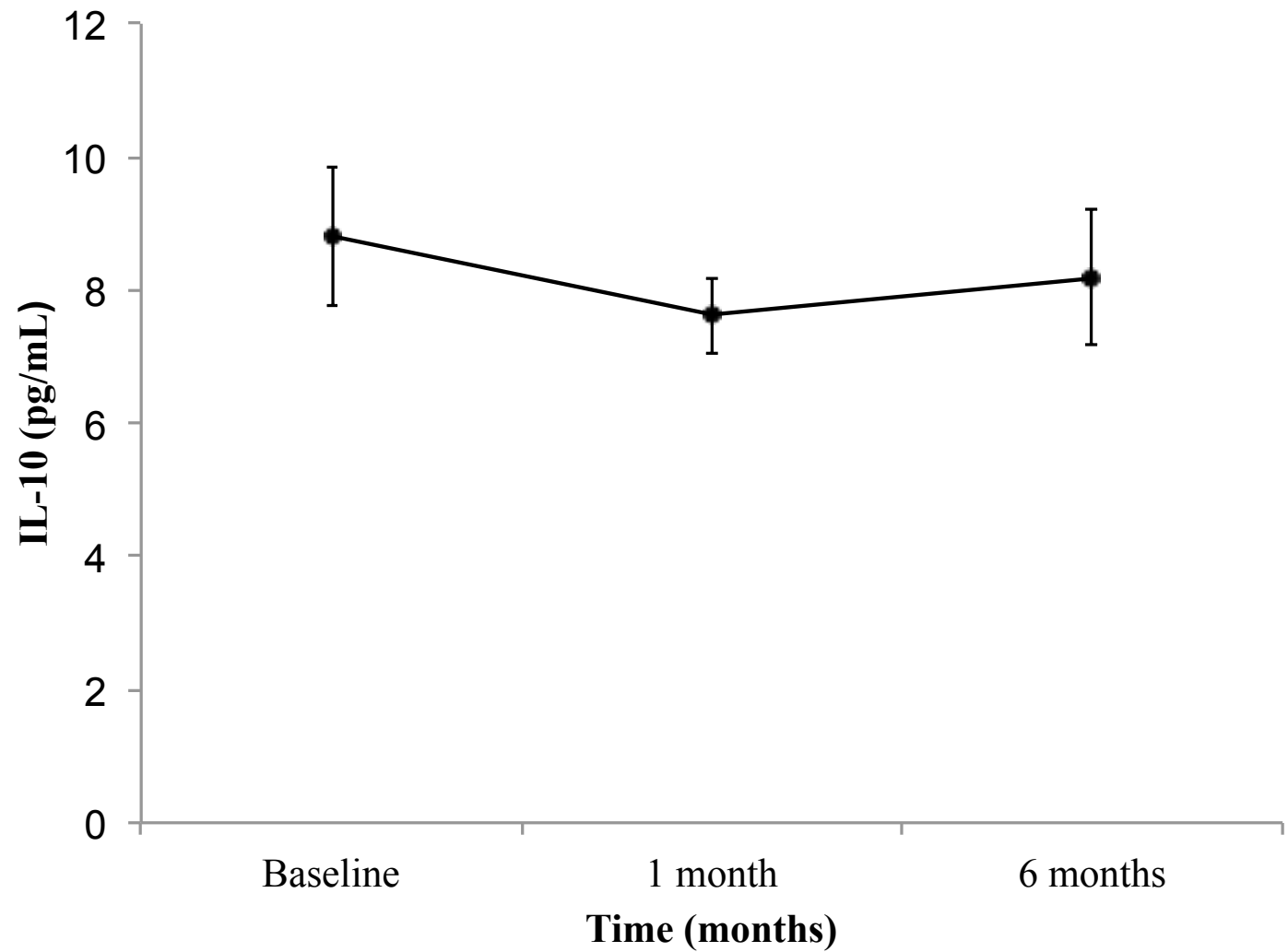

Figure 1b: Leptin

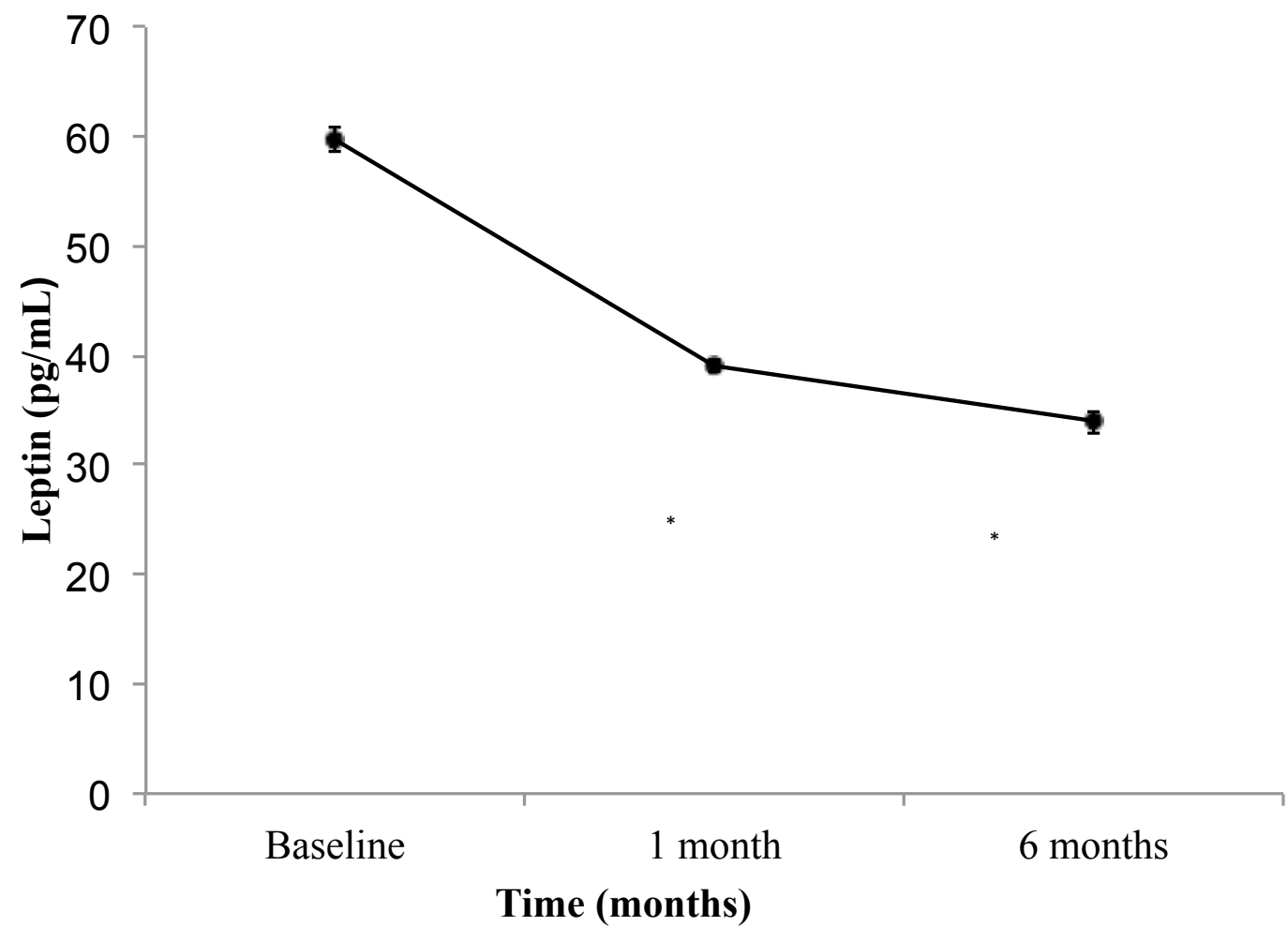


Figure 1c: Adiponectin

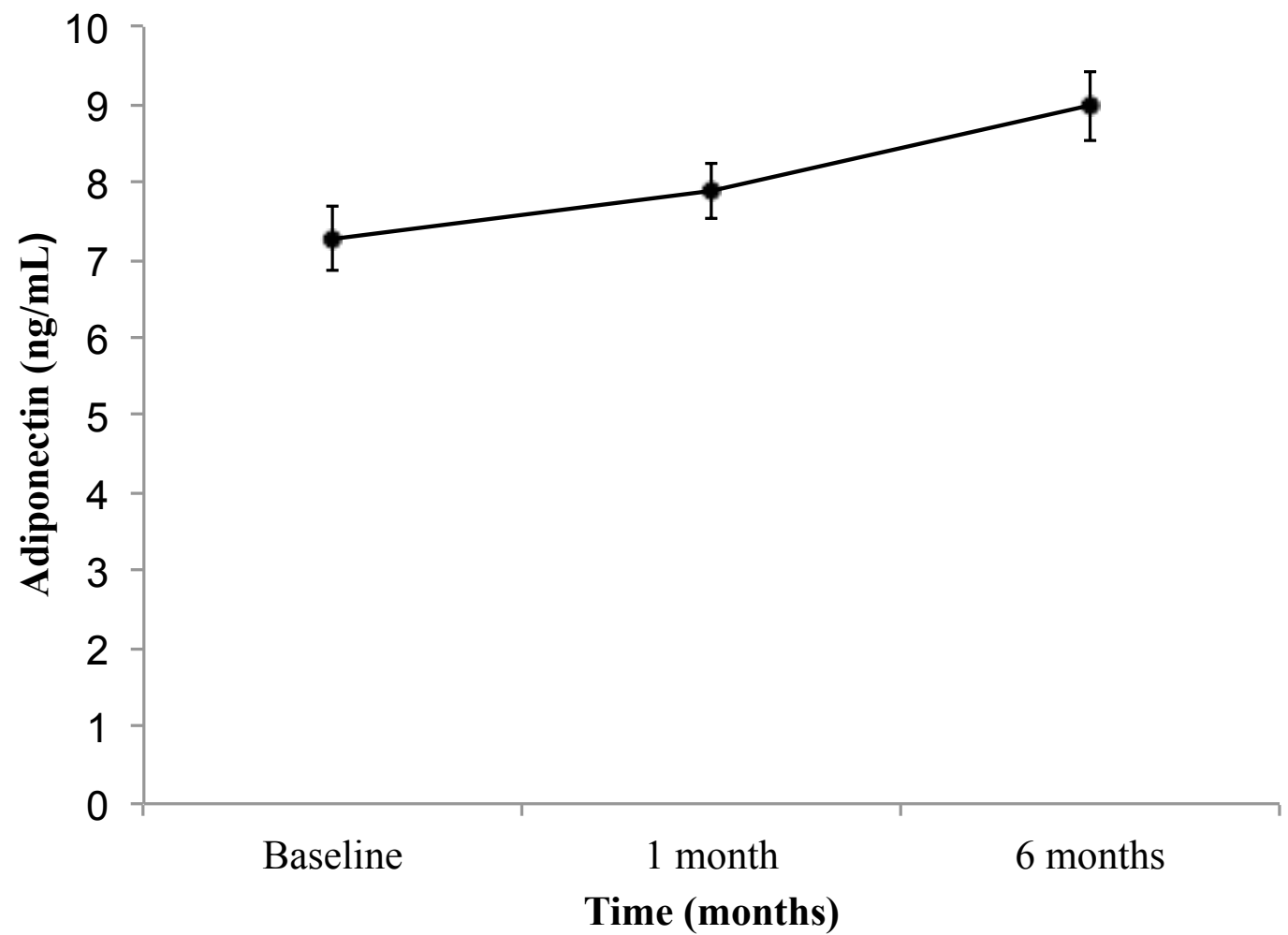

Figure 1d: C-reactive protein

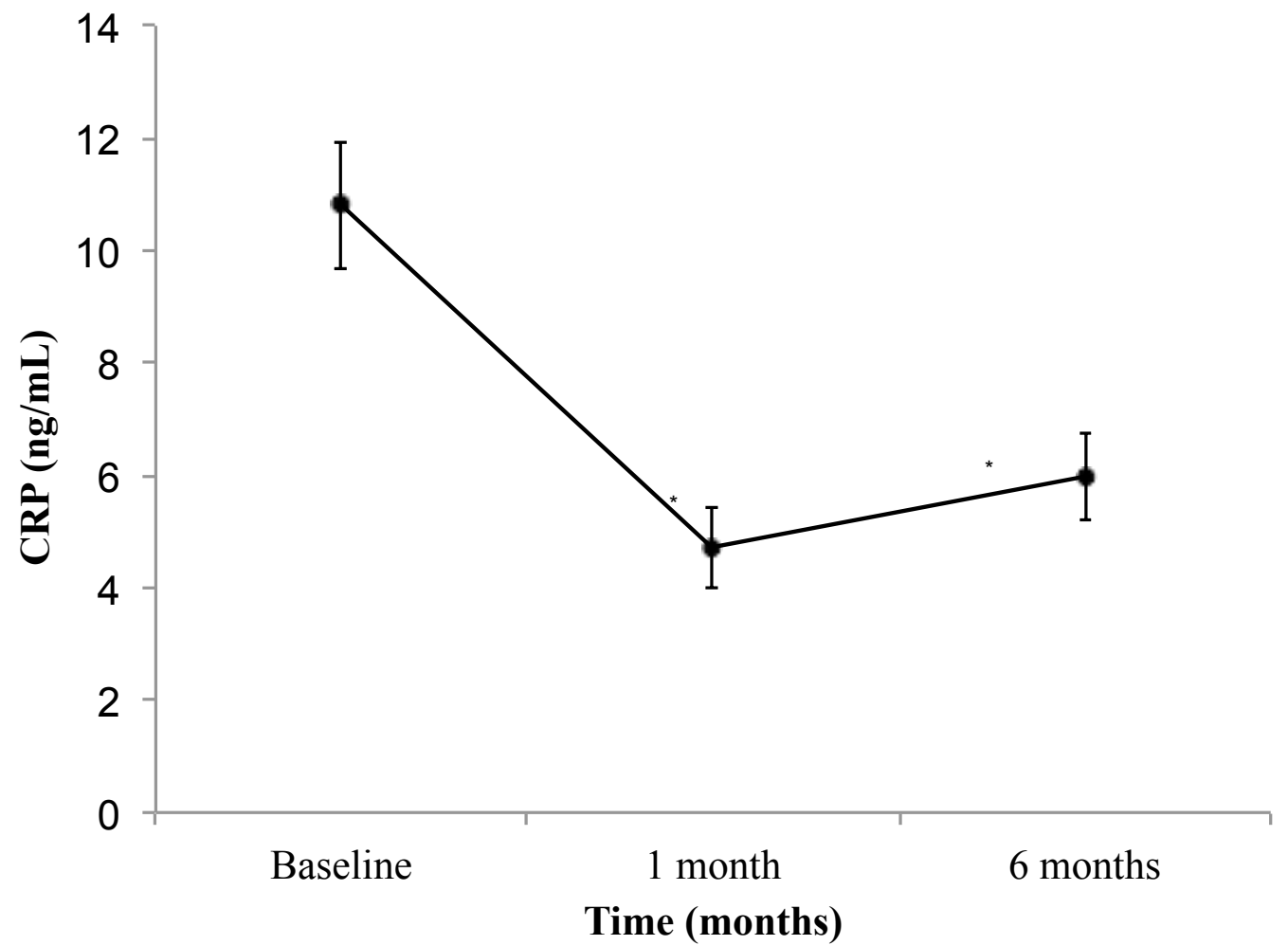


Figure 1e: Interleukin-6

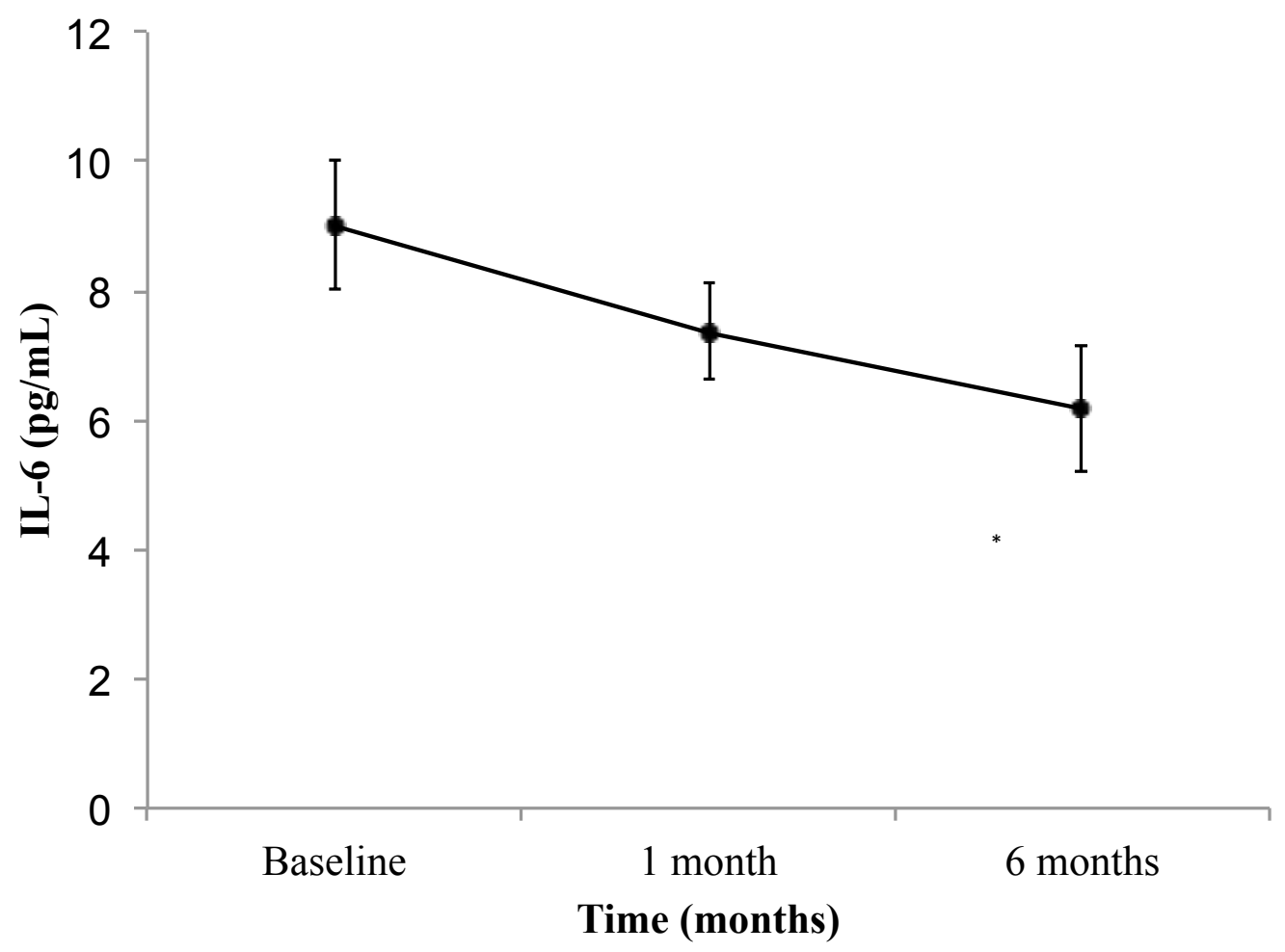

